\title{
Letter-detection patterns in German: A window to the early extraction of sentential structure during reading
}

\author{
JOCHEN MÜSSELER \\ Max Planck Institute for Psychological Research, Munich, Germany \\ ASHER KORIAT \\ University of Haifa, Haifa, Israel \\ and \\ MONIKA NIBLEIN \\ Max Planck Institute for Psychological Research, Munich, Germany
}

\begin{abstract}
Letters are more difficult to detect in function words than in content words, presumably because function words serve to cue sentential structure but recede to the background as meaning unfolds. This function disadvantage was found for the definite article in German for all three genders and all four cases, but it was more pronounced when the article appeared in a nominative noun phrase than in an object noun phrase. It was also more pronounced for the typical subject-predicate-object sentential format than for the object-predicate-subject sentential format and also when the definite article unequivocally specified the case of a phrase than when it was ambiguous. The results suggest that the structural frames established on line in reading are finely tuned to both phrase-level and sentence-level organization.
\end{abstract}

When readers are asked to circle a specific target letter in connected text, they are more likely to miss that letter in frequent function words (e.g., the) than in less common words (the missing-letter effect, MLE). This phenomenon has been widely replicated in many studies (see Healy, 1994). According to Healy's unitization model (e.g., Healy, 1976; Healy \& Drewnowski, 1983), the MLE is symptomatic of the size of the effective unit in reading. Readers process a text in parallel at several levels of analysis (e.g., letter, syllable, word, and phrase). Familiarity with a unit at a given level (e.g., word) permits fast access to its unitized representation, preempting access to lower level representations (e.g., letters). Therefore, highly familiar words tend to "conceal their letters."

Koriat and Greenberg (1994), in contrast, took the MLE as evidence for structural processing in reading. They argued that the words for which the MLE has been most clearly found (e.g., the, on, and to) not only are the most frequent in English but also serve a particular role in helping to define the structure of the sentence. According to their structural view, the analysis of structure precedes the

This research was supported by Grant DFG Mu 1298/3 from the German Science Foundation. The authors thank Carolyn Buck-Gengler, Mike Rinck, and an anonymous reviewer for their helpful comments to a previous version of the paper. Correspondence should be addressed to J. Müsseler, Max Planck Institute for Psychological Research, Amalienstr. 33, D-80799 München, Germany (e-mail: muesseler@ mpipf-muenchen. mpg.de). analysis of meaning and paves the way for it. Thus, on the basis of a shallow and rapid analysis of text, readers establish a tentative structural frame for the phrase or the sentence that can help to organize and integrate semantic information on line. Function words provide important cues for structure and are therefore monitored early in text processing. However, once a structural frame has been established, this frame, as well as the function words that support it, recedes to the background in favor of the semantically rich content words. Thus, function words are "missed" precisely because of their important structural contribution. This implies that the MLE occurs at a postlexical stage, after the function words have been interpreted and utilized in building structure. Indeed, function words, such as the, on, for, and in, have been found to produce no more errors than content words when they did not assume their typical, structure-supporting role in the sentence (Greenberg \& Koriat, 1991; Moravcsik \& Healy, 1995). Results also suggest that the MLE occurs before semantic analysis has been completed, because it was found in comparing nonwords placed in function slots with those placed in content slots in a sentence (Koriat \& Greenberg, 1991).

Overall, then, the MLE appears to disclose an intermediate representation, one that is formed after structural analysis has ended and before semantic analysis has been completed. What is the nature of this representation? Because structural analysis is assumed to occur on line, Koriat and Greenberg (1994) assumed that the tentative 
Table 1

Declination of the Definite Article in German

(der Mann = the man; die Frau = the woman; das Kind =the child $)$

\begin{tabular}{|c|c|c|c|c|c|c|}
\hline \multirow[b]{2}{*}{ Case } & \multicolumn{3}{|c|}{ Singular } & \multicolumn{3}{|c|}{ Plural } \\
\hline & Masculine & Feminine & Neuter & Masculine & Feminine & Neuter \\
\hline $\begin{array}{l}\text { Nominative } \\
\text { Genitive } \\
\text { Dative } \\
\text { Accusative }\end{array}$ & $\begin{array}{l}\text { der Mann } \\
\text { des Mannes } \\
\text { dem Mann } \\
\text { den Mann }\end{array}$ & $\begin{array}{l}\text { die Frau } \\
\text { der Frau } \\
\text { der Frau } \\
\text { die Frau }\end{array}$ & $\begin{array}{l}\text { das Kind } \\
\text { des Kindes } \\
\text { dem Kind } \\
\text { das Kind }\end{array}$ & $\begin{array}{l}\text { die Männer } \\
\text { der Männer } \\
\text { den Männern } \\
\text { die Männer }\end{array}$ & $\begin{array}{l}\text { die Frauen } \\
\text { der Frauen } \\
\text { den Frauen } \\
\text { die Frauen }\end{array}$ & $\begin{array}{l}\text { die Kinder } \\
\text { der Kinder } \\
\text { den Kindern } \\
\text { die Kinder }\end{array}$ \\
\hline
\end{tabular}

frames underlying the MLE reflect local structure, possibly phrase-level organization only. However, other results (Greenberg \& Koriat, 1991; Moravcsik \& Healy, 1995 ) suggest that these frames might be sensitive to structures that extend beyond phrase level - that is, those that disclose the organizational properties of the sentence as a whole. One aim of this study was to explore this possibility.

It should be stressed that the structural view of reading does not make any claims regarding the existence of an autonomous syntactic parser that is immune to the effects of context (e.g., Frazier, 1987). In fact, the MLE results obtained previously and those to be presented here also fit well with a constraint-based view of sentence processing according to which syntactic and semantic language comprehension is accomplished through the satisfaction of multiple constraints at different levels of representations (see MacDonald, 1996; but see Frazier, 1995). The only assumption of the present structural view is that the analysis of the structure of text precedes the analysis of its specific content and that function words provide useful cues for text structure; they are first utilized to set structure and then recede to the background in favor of the semantically rich content words.

Some of the evidence in support of the structural account of the MLE has come from Hebrew (Koriat \& Greenberg, 1994) and from French (Saint-Aubin \& Poirier, 1997). Both of these languages offer interesting research opportunities that are not available in English. The present study extended investigation of the MLE to German, for which first steps have been made by Buck-Gengler and Healy (1993). Once we have established the MLE for function words in German, we will then proceed to exploit some of the unique properties of German both to extend the applicability of the structural view and to obtain further insight into the process underlying structure extraction in reading.

The most striking demonstration of the MLE in English has been observed for the definite article. This article has only one form, the, and the is also the most frequent word in English. In contrast, German (like other Indo-European languages, e.g., French, Italian, or Russian) has several forms for the definite article (Table 1). For example, in the singular nominative case, the definite articles are der (for masculine), die (for feminine), and das (for neuter). In languages with a gender system, several studies indicated that the gender specification of the article serves as a powerful cue to the encoding of the subsequent noun (e.g., Bates, Devescovi, Hernandez, \& Pizzamiglio, 1996; Radeau \& van Berkum, 1996; Schriefers, Friederici, \& Rose, 1998). Perhaps, gender and case are also helpful cues for the specification of sentence structure in German. In Experiment 1, we used all three articles, der, die, and das, and examined whether the function-disadvantage effect is observed for each of them.

In Experiments 2-4, we made use of three features of German that distinguish it from English to explore subtle differences in the magnitude of the MLE. In Experiment 2, we examined differences in the size of the MLE for the definite article as a function of the case of the noun that it modifies (nominative, genitive, dative, and accusative). In Experiment 3, we examined the effects of different orderings of the phrases within the sentence, contrasting the subject-predicate-object format with the object-predicatesubject format. Finally, in Experiment 4, we examined how the ambiguity of a definite article interacts with sentential format and phrase case in affecting letter detection errors in the definite article. Taken together, these experiments were intended to show that the magnitude of the MLE for the definite article increases with the ease with which an effective structural frame can be established that can guide and organize the semantic analysis of the sentence as a whole.

\section{EXPERIMENT 1}

In Experiment 1, we examined the MLE for the three forms of the definite article in German, der, die, and das, all in the nominative singular. The availability of these three forms, all beginning with the same letter $(d)$ and all having a typical pronunciation (unlike the; see BuckGengler \& Healy, 1993; Healy, 1976), offers a good opportunity for a replication of the MLE in German. Because all nouns in German have an initial uppercase letter, we presented all materials in uppercase letters only.

\section{Method}

Participants. Twenty-five University of Munich students whose native language was German were paid for participating in the study.

Stimulus materials. Twelve matched pairs of sentences, one containing a critical function word and one containing a critical content word, were constructed. They contained the same number of words, and the critical word occupied the same position in both sentences. Each of the critical function words, der, die, or das, ap- 


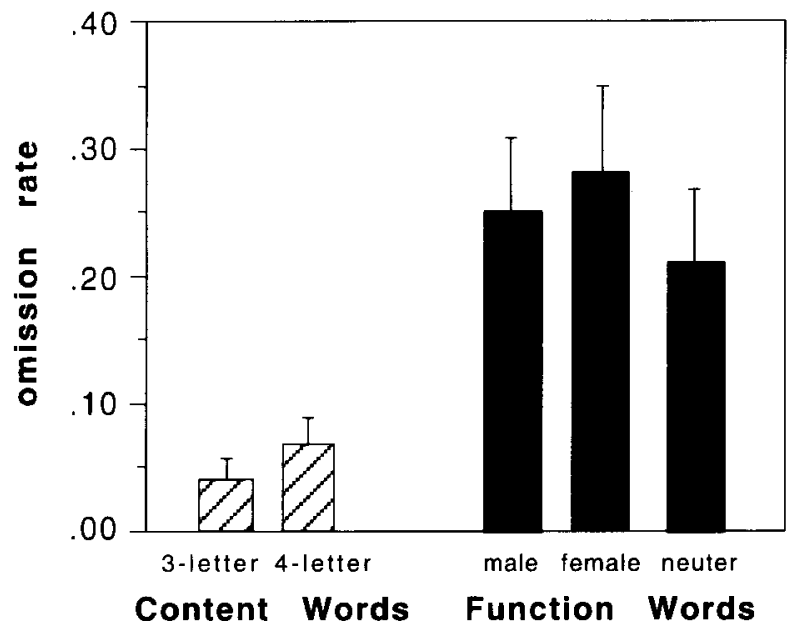

Figure 1. Omission rates (with standard errors between participants) plotted separately for three- and four-letter content words and for each of the three genders of function words in Experiment 1 .

peared in four sentences. The critical content words were either the three-letter nouns Dia (slide), Dom (cathedral), and Deo (deodorant) or the four-letter nouns Dorf(village), Dach (roof), and Dank (gratitude). The words are common nouns in German, ${ }^{1}$ and each was used in two different sentences (see below). The critical definite article was always used as a specifier of a subject-noun phrase in the singular nominative form. In isolation, these articles are ambiguous to various degrees regarding gender, case, and number (see Experiment 2 and Table 1). The critical content nouns were matched in case and number, since they were used as the heads of subjectnoun phrases.

All materials were compiled in a 3-page booklet. The first page contained the instructions and a practice passage, and the next 2 pages contained 12 sentences each. The sentences were assigned randomly to 1 of the 2 pages except that the two members of each pair were assigned to 2 different pages and that content and function sentences were equally represented on each page. Each target noun occurred only once on each page

In Experiment 1 and in all subsequent experiments, the order of sentences on a page was random, and the page appeared as one long paragraph of continuous text, composed of unrelated sentences (see, e.g., Koriat, Greenberg, \& Goldshmid, 1991). The critical word never occurred at the beginning or end of a sentence or of a line. Other $d$ s could appear in noncritical articles and nouns in the sentence but never in the word immediately preceding or following the critical word. These $d$ s were equally frequent in each pair of matched sentences. Two filler sentences were added at the beginning and end of each page. All sentences appeared in uppercase letters.

Procedure. The participants were instructed to read the sentences at their normal reading speed, but, whenever they came to the target letter $d$, they were to circle it. They were further instructed not to slow down their reading speed to catch all target letters and not to go back to circle a letter they had missed.

\section{Results and Discussion}

In Experiment 1 and all subsequent experiments, the rate of omission errors was used as the dependent variable. Statistical analyses were performed with arcsinetransformed error rates using participants $(\mathrm{P})$ and materials (M) as random factors. Mean omission rates for the critical function and content words was $.247(S E=.053$, always between participants) and $.053(S E=.016)$, respectively $\left[t_{\mathrm{P}}(24)=3.39 ; t_{\mathrm{M}}(22)=6.21\right.$; both significant at $p<.001]$. Thus, omission errors were considerably more frequent in function words than in content words, supporting the MLE for the definite article in German.

Note that omission rate did not differ between threeletter and four-letter content words $\left[t_{\mathrm{P}}(24)=1.28 ; t_{\mathrm{M}}(10)=\right.$ 0.60 ; both n.s.], and each of these means was smaller than that of the function words [for three-letter nouns, $t_{\mathrm{P}}(24)=3.48$, and $t_{\mathrm{M}}(16)=6.14$, both at $p<.001$; for four-letter nouns, $t_{\mathrm{P}}(24)=3.20$, and $t_{\mathrm{M}}(16)=4.20$, both $p<.01]$. This rules out an explanation of the MLE in terms of word length.

Figure 1 depicts the results separately for each of the function words, and for three-letter and four-letter content words. It can be seen that omission rate was consistently higher for each of the three forms of the definite article than for the content words. A one-way analysis of variance (ANOVA) comparing omission rate for the three function words yielded $F_{\mathrm{P}}(2,48)=1.53, M S_{\mathrm{e}}=0.068$, n.s., and $F_{\mathrm{M}}<1$. Furthermore, the means of the function words were higher than those of the content words [for masculine, $t_{\mathrm{P}}(24)=2.94$, and $t_{\mathrm{M}}(14)=4.42$, both $p \mathrm{~s}<$ .01 ; for feminine, $t_{\mathrm{P}}(24)=2.98$, and $t_{\mathrm{M}}(14)=4.16$, both $p \mathrm{~s}<.01$; for neuter, $t_{\mathrm{P}}(24)=2.70$, and $t_{\mathrm{M}}(14)=4.68$, both $p s<.01]$. These results support the generality of the MLE across the three forms of the definite article in German.

In sum, the results of Experiment 1 join with those reported earlier by Buck-Gengler and Healy (1993) in supporting the existence of a function-disadvantage effect in German. Omission rate was nearly five times higher in function words than in content words. This difference is impressive in view of the fact that the MLE for uppercase text has been found somewhat smaller than that for normal text (Drewnowski \& Healy, 1977). These results are consistent with those obtained in English (Healy, 1994), in Hebrew (Koriat \& Greenberg, 1994), and in French (Saint-Aubin \& Poirier, 1997), suggesting that the function-disadvantage effect reveals some aspect of the reading process that may be universal.

Having established the function-disadvantage effect in German, we now proceed to exploit some of the particular features of German to clarify the extraction of structure assumed to take place early in text processing. We propose that the magnitude of the MLE for a definite article varies with the extent to which this article helps disclose the organization of the sentence as a whole. Hence, any factor that facilitates the smooth extraction of sentential structure should enhance the magnitude of the functiondisadvantage effect.

\section{EXPERIMENT 2}

In Experiment 1, we confined our investigation to the nominative case. However, German morphology differentiates between four cases, each case being associated 
with a particular syntactic (or even thematic) role. The definite article assumes different forms in each of these cases, and its structural role may be somewhat more circumscribed than that of the in English.

A brief clarification is needed for readers unfamiliar with German. Consider the masculine singular forms. In addition to the nominative form der, the genitive form des corresponds to of the, the dative form dem corresponds to to the, and the accusative form den corresponds to the when used to introduce a direct object. Some complications emerge, however, as can be seen in Table 1. For example, the feminine singular article die and the neuter singular article das do not differentiate morphologically between the nominative and accusative cases. Similarly, the article der can imply different roles, because it is compatible with masculine singular nominative, feminine singular genitive, feminine singular dative, or plural genitive. Note that, in comparison with English, the definite article in German sometimes assumes a meaning that would correspond to a sequence of two function words in English (of the or to the). Given the morphological ambiguities sketched above, the interpretation of a definite article in German is therefore still dependent on sentential context. For example, der Baum means the tree, whereas der Blume could either mean of the flower or to the flower. In order to discern between these meanings of der, one has to know that Baum is masculine and Blume is feminine, but one also has to know whether der Blume, for example, is an indirect object or a genitive modifier.

These complications should pose a problem of interpretation for the German reader that hardly exists in the case of the definite article in English. How does that problem affect the analysis of structure and letter detection? One might expect that because the interpretation of the definite article in German is context dependent, its usefulness as a cue for structure might be limited. However, in Hebrew, for example, the MLE was found even for an initial letter of a word when it stood for a function prefix than when it was part of the stem, suggesting that function morphemes can help in cuing structure even when their identification as a function morpheme depends on context. Therefore, it is our view that, in German, the definite article should also help structural analysis regardless of its ambiguity or the case of the noun that it specifies.

Nevertheless, we expect the magnitude of the MLE to be particularly strong for the nominative subject phrase because of its special contribution to the structure of the sentence as a whole. Indeed, several observations suggest that the nominative subject phrase plays a more significant role in the processing of a sentence than the object phrase. For example, van Dijk and Kintsch (1983; see also Ferreira, 1994; Givon, 1992) proposed that the initial subject phrase typically determines the topic of a sentence or an episode. The subject phrase tends also to be the preferred referential position (Crawley, Stevenson, \& Kleiman, 1990; Grober, Beardsley, \& Caramazza, 1978; Müsseler, 1995; for discussions of the focus and topic issue see, e.g., Moravscik \& Healy, 1998, and Sidner, 1983). Thus, Experiment 2, tested the hypothesis that the MLE should be found for all cases but should be most pronounced for the nominative subject phrase.

\section{Method}

Participants. Forty-three University of Munich students served as paid participants.

Stimulus materials. For each of the four German cases, 10 matched pairs of sentences were constructed, with one member of each pair containing the respective form of the definite article, and the other containing a critical content word beginning with the letter $d$. The two members of each pair were matched in terms of the number of words and the position of the critical word within the sentence. All critical words appeared in their singular forms.

The critical content words are common four-letter nouns in German, all beginning with $d$. They included eight masculine nouns, seven feminine nouns, and five nouns of a neuter gender. Each was used in two sentences, so that altogether there were 40 content sentences, 10 sentences in each case. The function sentences were constructed so that the gender and case of the definite article were the same as those of the noun in the matched content sentence. The order of the sentences was random except that one member of each pair of sentences was assigned to the first two pages, whereas the other was assigned to the last two pages. Note, that although the design for the function sentences requires 12 ( 3 genders $\times 4$ cases) different forms of the definite article, there are actually only six different forms in German (der, die, das, dem, den, des), each of which is used to represent different combinations of case, gender, and number (see Table 1).

One complication in constructing the sentences is that the genitive case had to be used only with the feminine gender, because otherwise an additional word suffix would have had to be added to the noun, and this would have produced an undesirable increase in word length (e.g., in German, the genitive of a thief is eines Diebes; cf. des Mannes in Table 1). Therefore, des was excluded from sentence construction.

Procedure. The instructions and practice were the same as those of Experiment 1.

\section{Results and Discussion}

As may be clearly seen in Figure 2, the functiondisadvantage effect was observed for all cases and was particularly strong not only for the nominative case but also for the genitive case. The genitive case is peculiar in that it only specifies another concept (see below) and hence can be embedded either in a nominative subject phrase or in a dative or accusative object phrase. We shall therefore confine the analysis to the three remaining cases first and then examine the results for the genitive case separately.

Considering only the nominative, accusative, and dative cases, a word class (2) $\times$ case (3) ANOVA yielded significantly more omission errors in function words than in content words $\left[F_{\mathrm{P}}(1,42)=18.26, M S_{\mathrm{e}}=0.049, p<\right.$ $\left..001 ; F_{\mathrm{M}}(1,54)=77.07, M S_{\mathrm{e}}=0.003, p<.001\right]$. Case yielded a significant effect only in the analysis of participants $\left[F_{\mathrm{P}}(2,84)=3.47, M S_{\mathrm{e}}=0.006, p<.05 ; F_{\mathrm{M}}(2,54)=\right.$ $1.78, M S_{\mathrm{e}}=0.003$, n.s.], which was qualified by an interaction $\left[F_{\mathrm{P}}(2,84)=3.62, M S_{\mathrm{e}}=0.007, p<.05 ; F_{\mathrm{M}}(2,54)=\right.$ $\left.2.42, M S_{\mathrm{e}}=0.003, p<.10\right]$. The interaction reflects the 


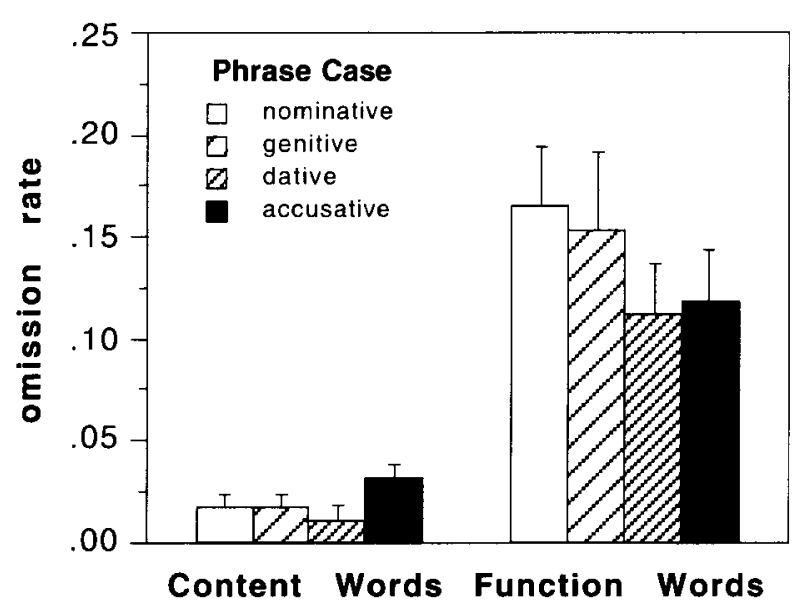

Figure 2. Omission rates for content and function words for the four different cases in Experiment 2.

observation that, for function words, omission rate was higher in the nominative case $(.165, S E=.029)$ than in the dative case $(.112, S E=.026)$ and the accusative case $(.116, S E=.028)$, whereas no similar difference was found for the matched content words $(.016, S E=.007$, for the nominative; $.012, S E=.006$, for the dative; and $.030, S E=$ .008 , for the accusative case).

Separate word class $\times$ case ANOVAs comparing error rates for the nominative case with each of the other cases yielded nearly significant interactions for the dative case $\left[F_{\mathrm{p}}(1,42)=3.78, M S_{\mathrm{e}}=0.007, p<.06 ; F_{\mathrm{M}}(1,36)=3.17\right.$, $\left.M S_{\mathrm{e}}=0.002, p<.09\right]$ and significant interactions for the accusative case $\left[F_{\mathrm{p}}(1,42)=6.73, M S_{\mathrm{e}}=0.006, p<.05\right.$; $\left.F_{\mathrm{M}}(1,36)=4.21, M S_{\mathrm{e}}=0.003, p<.05\right]$. Similar two-way ANOVAs comparing the accusative and dative cases, on the other hand, yielded nonsignificant interactions (both $\left.F_{\mathrm{s}}<1\right)$. Thus, the results confirm our hypothesis, indicating a stronger function disadvantage for the definite article when it is embedded in a nominative subject phrase than when it is embedded in a dative or accusative object phrase. Note that the inordinately high error rates for the nominative case was entirely confined to function sentences, because the content sentences yielded very similar error rates for all cases $\left[F_{\mathrm{p}}(2,84)=2.04, M S_{\mathrm{e}}=0.002\right.$, n.s.; $F_{\mathrm{M}}(2,27)=1.06, M S_{\mathrm{e}}=0.001$, n.s.].

Let us turn now to the genitive case. As noted above, the definite article in the genitive case may either specify the subject in a nominative subject phrase (e.g., "the dog of the man is playing on the lawn") or the noun in an object phrase (e.g., "he gave the bone to the dog of the man"). Do the two uses differ in the magnitude of the functiondisadvantage effect? To answer this question, all genitive sentences were classified post hoc into two groups according to whether the critical word was embedded in a nominative subject phrase or in an object phrase. It turned out that there were seven and three sentence pairs, respectively, in these two groups. For the function sentences, omission rate was higher for the nominative sub- ject phrase $(.170, S E=.080)$ than for the object phrase $(.117, S E=.064)$, producing a significant and a nearsignificant interaction in the word class (content vs. function) $\times$ phrase (subject vs. object noun phrase) ANOVAs $\left[F_{\mathrm{P}}(1,42)=4.43, M S_{\mathrm{e}}=0.006, p<.05 ; F_{\mathrm{M}}(1,16)=3.77\right.$, $\left.M S_{\mathrm{e}}=0.03, p \leq .07\right]$. This result confirms the previous analysis, but it indicates that the critical factor affecting the size of the function disadvantage is not case per se but rather whether the functor is embedded in a subject phrase or in an object phrase (but see also Moravcsik \& Healy, 1998). However, in the present experiment, the contrast between subject and object phrases was confounded with the location of the definite article in the sentence, because in German, like in English, subject phrases usually precede object phrases. This factor was not controlled in the construction of the sentences of Experiment 2. In Experiment 3, we investigate how the MLE is affected by the global structure of the sentence, and the design also allowed us to assess the effects of syntactic role independent of that of phrase location within the sentence. The flexibility of word order in German makes it easier to make such an assessment without the need to resort to more complex schemes such as those needed when using English (see Moravcsik \& Healy, 1995, 1998).

\section{EXPERIMENT 3}

As noted earlier, in German, sentence format can be handled with some flexibility. As illustrated in Example 1 (below), it is possible to use either the standard subjectpredicate-object (SPO) format, or the reverse, objectpredicate-subject (OPS) format. Although studies using subjective ratings and reproduction time have shown the standard SPO format to be more acceptable than the OPS format (Pechmann, Uszkoreit, Engelkamp, \& Zerbst, 1996; Rösler, Pechmann, Streb, Röder, \& Henninghausen, 1998), both formats are syntactically correct. However, if speakers or writers wish to convey a certain emphasis - for example, putting the stress on the dative object-the OPS format may be preferred over the SPO format.

Example 1:

(a) SPO: Der Autor profitierte von dem Bestseller. (The author profited from the best seller.)

(b) OPS: Von dem Bestseller profitierte der Autor. (From the best seller profited the author.)

If letter-detection patterns are symptomatic not only of single phrase structures but also of the organization of the phrases within a sentence, then the size of the functiondisadvantage effect should vary with the global organization of the sentence. It may be assumed that the typical SPO format is the one expected by readers, and it affords an easier establishment of a tentative structural frame (see the constraint-based view, MacDonald, 1996; see also Steinhauer, Mecklinger, Friederici, \& Meyer, 1997). In the case of the OPS format, more effort might be needed 


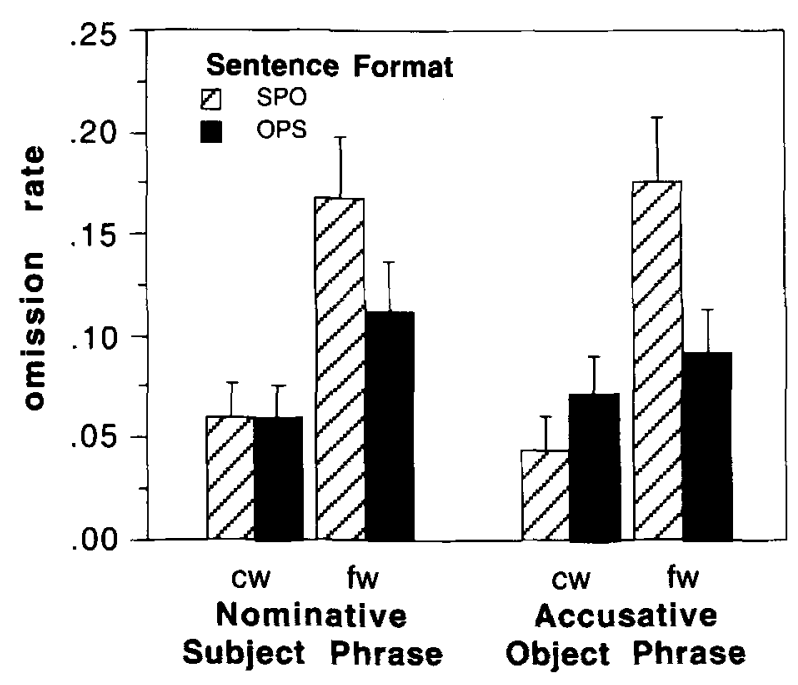

Figure 3. Omission rates for content and function words embedded in nominative and accusative phrases for sentences with subject-predicate-object (SPO) and object-predicate-subject (OPS) format in Experiment 3. $\mathrm{cw}=$ content words; $\mathrm{f} w=$ function words.

to decipher the syntactic structure of the sentence, or some transformation of the OPS format into the standard format might have to be performed (see Hemforth, 1993; Konieczny, Hemforth, Scheepers, \& Strube, 1996; Mecklinger, Schriefers, Steinhauer, \& Friederici, 1995). Either of these should result in a less pronounced MLE for the OPS format.

In Experiment 3, two versions of each sentence were constructed, which differed only in format (i.e., word order), SPO or OPS. In addition, the critical words were placed either in a nominative subject phrase or in an accusative object phrase.

\section{Method}

Participants. Fifty paid University of Munich students participated in the experiment.

Stimulus materials. For the SPO format, 20 content sentences were constructed, containing one of the 20 critical four-letter content words of Experiment 2 . In 10 of these, the critical word appeared in a nominative subject phrase, whereas, in the other 10 , it appeared in an accusative object phrase. The 20 words were as signed randomly to the two types of phrases. For each content sentence, a matched function sentence was constructed that had the same number of words, but in which a critical definite article was placed in nearly the same ordinal position as the corresponding content word in the content sentence. The gender of the definite article was the same as that of the critical content word in the matched content sentence. The critical words were always in the singular form.

One complication that emerged is that, in the SPO format, the definite article in a subject phrase generally occupies the initial position in the sentence. To avoid this situation, the definite article always appeared in the context of a coordinating structure: The subject phrase had two parts connected with und (and), sowohl ... als auch (as well as), weder... noch (neither... nor), nicht nur... sondern auch (not only ... but also), and so on (see Appendix A). For the same reason, the critical word in the object phrases was preceded by an adverbial specifier, such as häufig (often), immer (always), and so on, or by a preposition such as bis (until), auf (upon), and so on.

For each SPO sentence, a matched OPS sentence was composed that differed from it only in the format of the words within the sentence-that is, the order of the constituent phrases. Altogether, then, there were 80 sentences representing all combinations of sentence format (SPO vs. OPS), case (nominative vs. accusative), and word class (content vs. function), with 10 sentences in each combination. The SPO and OPS versions of each sentence were assigned randomly to two different booklets, with the restriction that all factorial combinations were equally represented in each booklet.

Procedure. Each of the two types of booklets was administered to 25 participants. The general procedure was the same as that of Experiment 1.

\section{Results and Discussion}

Because the accusative and nominative sentences were not entirely matched in terms of their construction, we first report the analyses for each of the two cases separately. For the nominative case, sentence format (SPO vs. OPS) $\times$ word class (content vs. function) ANOVAs yielded the typical function-disadvantage effect $\left[F_{\mathrm{P}}(1,49)=7.87\right.$, $M S_{\mathrm{e}}=0.050, p<.01 ; F_{\mathrm{M}}(1,36)=14.93, M S_{\mathrm{e}}=0.044$, $p<.001]$. Sentence format had no effect on letter detection $\left[F_{\mathrm{P}}(1,49)=2.74, M S_{\mathrm{e}}=0.022\right.$, n.s.; $F_{\mathrm{M}}(1,36)=1.85$, $M S_{\mathrm{e}}=0.044$, n.s. $]$. However, the interaction was significant in the participants-based ANOVA $\left[F_{\mathrm{P}}(1,49)=4.15\right.$, $\left.M S_{\mathrm{e}}=0.014, p<.05\right]$, but not in the materials-based ANOVA $\left[F_{\mathrm{M}}(1,36)=1.85, M S_{\mathrm{e}}=0.044\right]$.

ANOVAs for the accusative sentences yielded similar results $\left[F_{\mathrm{P}}(1,49)=11.67, M S_{\mathrm{e}}=0.028, p \leq .001\right.$, and $F_{\mathrm{M}}(1,36)=12.06, M S_{\mathrm{e}}=0.005, p \leq .001$, for word class; $F_{\mathrm{P}}(\mathrm{i}, 49)=2.78, M S_{\mathrm{e}}=0.018$, n.s., and $F_{\mathrm{M}}(1,36)=1.65$, $M S_{\mathrm{e}}=0.005$, n.s., for sentence format; and $F_{\mathrm{p}}(1,49)=$ $8.75, M S_{\mathrm{e}}=0.020, p \leq .005$, and $F_{\mathrm{M}}(1,36)=6.58, M S_{\mathrm{e}}=$ $0.005, p<.05$, for the interaction]. As may be seen in Figure 3 , the SPO format yielded a stronger function disadvantage than did the OPS format, exhibiting a higher rate of detection errors in function words $(.168, S E=.030$, and $.176, S E=.031$, compared with $.112, S E=.024$, and $.092, S E=.021$, for the OPS format).

Finally, when phrase case (nominative vs. accusative) was included as a third factor in a three-way ANOVA, significant effects were again found for word class $\left[F_{\mathrm{P}}(1,49)=\right.$ $13.59, M S_{\mathrm{e}}=0.052, p \leq .001 ; F_{\mathrm{M}}(1,72)=26.81, M S_{\mathrm{e}}=$ $0.005, p<.001]$, for sentence format $\left[F_{\mathrm{p}}(1,49)=4.75\right.$, $M S_{\mathrm{e}}=0.023, p<.05 ; F_{\mathrm{M}}(1,72)=3.50, M S_{\mathrm{e}}=0.005, p<$ $.07]$, and for the word class $\times$ sentence format interaction $\left[F_{\mathrm{P}}(1,49)=16.13, M S_{\mathrm{e}}=0.013, p<.001 ; F_{\mathrm{M}}(1,72)=\right.$ 7.83, $\left.M S_{\mathrm{e}}=0.005, p<.01\right]$. Phrase case (nominative vs. accusative) had no main or interactive effects. ${ }^{2}$

It should be noted that although the nonstandard OPS format yielded a reduced MLE, the effect was nevertheless significant. Overall, rate of omission errors for function and content words in the OPS format averaged 102 $(S E=.019)$ and $.066(S E=.014)$, respectively $\left[t_{\mathrm{p}}(49)=\right.$ $1.76 ; t_{\mathrm{M}}(38)=1.71$; both $\left.p \mathrm{~s}<.05\right]$. Note also that the difference in error rate between the SPO and OPS formats was entirely due to the function sentences: Separate 
ANOVAs for function sentences yielded significant effects for format $\left[F_{\mathrm{p}}(1,49)=13.77, M S_{\mathrm{e}}=0.023, p \leq .001\right.$; $\left.F_{\mathrm{M}}(1,36)=8.10, M S_{\mathrm{e}}=0.006, p<.01\right]$, whereas similar ANOVAs for content sentences always yielded $F<1$.

In sum, target letters in function words are more likely to be missed if they appear in a standard SPO format than if they appear in an OPS format. This is true both for the nominative case and for the accusative case. Note that, in the SPO format, the critical word appears within the first noun phrase of the sentence in the nominative case, but it appears within the last noun phrase in the accusative case. The opposite is true for the OPS format. Hence, the position of the word within the sentence can be ruled out as an explanation of the SPO-OPS difference observed. Rather, this difference seems to be related to the structure of the sentence as a whole.

Altogether, the results support the proposition that the extraction of a structural frame is sensitive not only to phrase structure but also to the organization of phrases within a sentence. The stronger MLE found for the SPO format is consistent with the idea that this format is assumed by readers as the default format. Indeed, the SPO format is judged to be the more acceptable and is also more easily reproduced than the OPS format (Pechmann et al., 1996; Rösler et al., 1998). Thus, the SPO format would seem to be more favorable for the early extraction of structure during reading, yielding a sharper contentfunction distinction in letter detection. At the same time, the function-disadvantage effect observed for the nonstandard OPS format suggests that letter detection is sensitive to the structural organization of the phrase, even when the phrase is embedded in a nonstandard sentential structure.

\section{EXPERIMENT 4}

How is the organization of the whole sentence extracted on line during reading? Presumably, the initial phrase of a sentence can prepare the reader for a standard SPO organization of the sentence as a whole. Thus, an initial phrase with a nominative case can signal an SPO format as opposed to an OPS format. However, the case of a single phrase in German cannot always be specified unequivocally without consideration of the sentence in which it is embedded. Therefore, the format of the sentence cannot always be inferred from the initial phrase of that sentence. Consider, for example, the following sentences:

Example 2:

Masculine gender, plain noun phrases

(der Schauspieler, den Schauspieler)

(a) SPO: Der Schauspieler verbreitet Langeweile. (The actor spreads boredom.)

(b) OPS: Den Schauspieler findet der Kritiker langweilig.

(The actor [is] judged [by] the critic [to be] boring.)

Feminine gender, ambiguous noun phrases (die Dame)

(c) SPO: Die Dame trinkt den Tee auf die englische Art.

(The lady drinks the tea in the English manner.)

(d) OPS: Die Dame findet der Kavalier attraktiv. (The lady [is] judged [to be] attractive [by] the gentleman.)

The initial phrase in Example 2a can be assigned unequivocally to the nominative case, and that in Example $2 b$ can be assigned unequivocally to the accusative case. Such is not the case with the initial phrases of Examples $2 \mathrm{c}$ and $2 \mathrm{~d}$. This is because, in German, the definite articles for the nominative and accusative cases differ only in the masculine gender (e.g., der Schauspieler vs. den Schauspieler [the actor]) but not in the feminine or neuter genders (e.g., die Dame [the lady]). When die Dame appears at the beginning of a sentence, it is ambiguous with respect to case, and only the subsequent verb and the following phrases can help disambiguate it. In Example 2c, the verb trinkt and the second phrase den Tee specify die Dame as nominative, whereas, in Example 2, der Kavalier must be nominative because Kavalier is masculine and der is only nominative with masculine singular nouns. Therefore, in Example 2d, die Dame is accusative. ${ }^{3}$

Whether the case of a phrase is ambiguous or unambiguous should make a difference not only for the specification of the structure of that phrase but also for that of the sentence as a whole. Thus, the opening phrase in Example $2 \mathrm{c}$ should be less effective for signaling the SPO format than the initial phrase in Example 2a. If the MLE is indeed sensitive to expectations about the structure of the whole sentence, then the effect of sentence format should be found only for sentences whose initial phrase is unambiguous (like Examples $2 a$ and $2 b$ ). Furthermore, the magnitude of the MLE should be sensitive to case ambiguity, being stronger for unambiguous noun phrases, because such phrases allow a more fluent and smooth establishment of a structural frame.

The design of Experiment 4 was similar to that of Experiment 3, except for two modifications: The critical phrases were always the leading phrases in the experimental sentences, and the ambiguity of the case of the initial noun phrase was systematically manipulated.

\section{Method}

Participants. Fifty-four university students were paid for participating in the experiment.

Stimulus materials. Sixteen sentences were constructed for each of eight factorial combinations resulting from the crossing of three factors: case ambiguity (plain vs. ambiguous phrases), word class (content vs. function word), and case of the leading phrase (nominative vs. accusative). Thus, 128 sentences were used (for examples of the function-word sentences see Appendix B).

Case ambiguity was manipulated by the choice of gender. For half of the experimental sentences, a masculine gender was used; for the remaining sentences, it was equally divided between the neuter and feminine genders. As noted earlier, case assignment is unequivocal for masculine phrases, because the critical definite article differs 


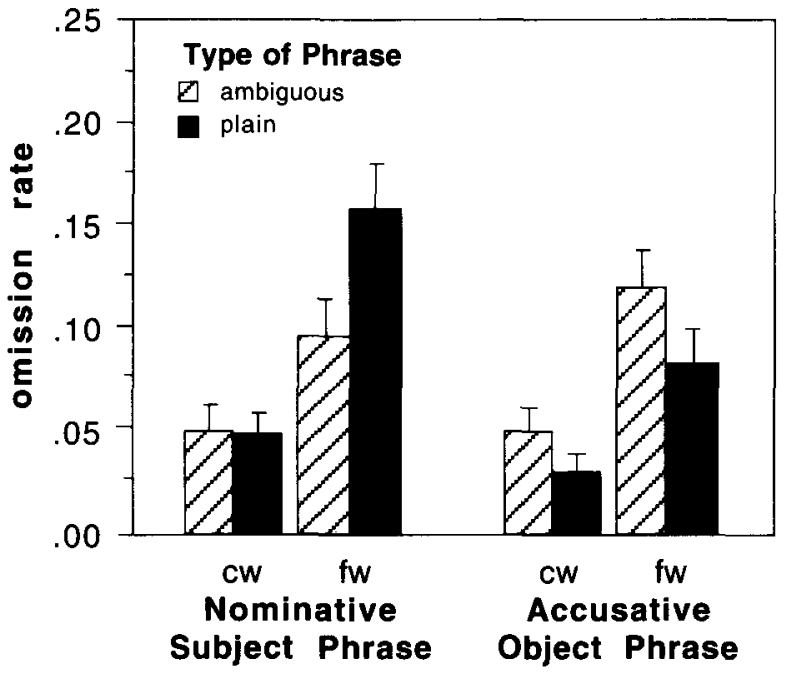

Figure 4. Omission rates for content and function words for ambiguous and plain nominative and accusative phrases in Experiment $4 . \mathrm{cw}=$ content words; $\mathrm{f} w=$ function words.

for the nominative (der) and accusative cases (den), as illustrated by Examples $2 \mathrm{a}$ and $2 \mathrm{~b}$. For the neuter and feminine phrases, in contrast, the same form (die or das) is used in both cases, and final case assignment must therefore rely on subsequent information (Examples $2 \mathrm{c}$ and $2 \mathrm{~d}$ )

Half of the sentences were function sentences-that is, the critical word in the critical phrase was a definite article, either der (nominative) or den (accusative) in the plain phrases and either die or das (used in both the nominative and accusative cases) in the ambiguous phrases. Each of the remaining 64 sentences, which contained a critical content word, was matched with one of the function sentences in terms of case, gender of the critical word, number of words, and the position of the critical word. The critical content words, taken from Experiment 2, included eight masculine nouns, four feminine nouns, and four neuter nouns.

Furthermore, the critical word was placed equally often in a nominative phrase or in an accusative phrase. In the case of content sentences, the critical content word appeared twice in a critical nominative phrase and twice in a critical accusative phrase. The critical phrases always occupied the initial position of the sentence, so that sentences embodying a critical nominative phrase were always in the SPO format and those embodying a critical accusative phrase were always in the OPS format. Unlike in Experiment 3, in Experiment 4 , an additional filler sentence (presentence) preceded every experimental sentence. The presentence was introduced to prevent the critical words from occurring at the very beginning of a sentence. It consisted of a syntactically independent sentence part, which was joined with the critical sentence by aber (but), auch (also), denn (because), und auch (and also), or just a comma

Procedure. The SPO and OPS sentences were randomly assigned to two different booklets, each of which was administered to 27 participants. The general procedure was the same as that of Experiments $1-3$.

\section{Results and Discussion}

Figure 4 presents mean omission rates for function and content words in ambiguous and plain phrases in the nominative subject phrase and the accusative object phrase. Three-way ANOVAs, with word class (content vs. function) $\times$ phrase (subject vs. object) $\times$ ambiguity (plain vs. ambiguous), yielded significant effects for word class $\left[F_{\mathrm{p}}(1,53)=24.55, M S_{\mathrm{e}}=0.023, p<.001\right.$; $\left.F_{\mathrm{M}}(1,120)=47.32, M S_{\mathrm{e}}=0.003, p<.001\right]$, indicating a function disadvantage. Phrase yielded nearly significant effects in both analyses $\left[F_{\mathrm{P}}(1,53)=3.89, M S_{\mathrm{e}}=0.010\right.$, $\left.p<.06 ; F_{\mathrm{M}}(1,120)=3.22, M S_{\mathrm{e}}=0.003, p<.08\right]$, but what is important is its interaction with ambiguity $\left[F_{\mathrm{P}}(1,53)=\right.$ $12.90, M S_{\mathrm{e}}=0.077, p \leq .001 ; F_{\mathrm{M}}(1,120)=8.52, M S_{\mathrm{e}}=$ $0.003, p<.005$ ]. Also important is the significant threeway interaction $\left[F_{\mathrm{P}}(1,53)=5.78, M S_{\mathrm{e}}=0.083, p<.05\right.$; $\left.F_{\mathrm{M}}(1,120)=4.14, M S_{\mathrm{e}}=0.003, p<.05\right]$. This interaction reflects the observation that only function words yielded the following pattern: In nominative sentences, $d \mathrm{~s}$ were more often missed in plain phrases than in ambiguous phrases $(.160, S E=.023$, and $.097, S E=.017$, respectively), whereas, in accusative sentences, the opposite pattern was obtained (.083, $S E=.017$, and $.120, S E=.019)$.

Thus, focusing on plain phrases only, it appears that the magnitude of the MLE is more pronounced in nominative subject phrases than in accusative object phrases. Indeed, a two-way, word class $X$ subject versus object phrase, ANOVA for these phrases yielded significant effects for word class $\left[F_{\mathrm{P}}(1,53)=24.66, M S_{\mathrm{e}}=0.016, p<\right.$ $\left..001 ; F_{\mathrm{M}}(1,60)=40.68, M S_{\mathrm{e}}=0.002, p<.001\right]$, for subject versus object phrase $\left[F_{\mathrm{P}}(1,53)=12.52, M S_{\mathrm{e}}=0.010\right.$, $\left.p \leq .001 ; F_{\mathrm{M}}(1,60)=13.59, M S_{\mathrm{e}}=0.002, p<.001\right]$, and for the interaction $\left[F_{\mathrm{P}}(1,53)=6.25, M S_{\mathrm{e}}=0.008, p<.05\right.$; $\left.F_{\mathrm{M}}(1,60)=5.28, M S_{\mathrm{e}}=0.002, p<.05\right]$. Recall that the critical word was always placed in the initial phrase of the critical sentence part. Therefore, the critical nominative subject phrase was always embedded in the SPO format, whereas the critical accusative object phrase was embedded in the OPS format. Thus, this finding replicates the result of Experiment 3 of more omission errors in the typical SPO format than in the atypical OPS format.

A further finding is that phrase ambiguity moderated the magnitude of the MLE for subject noun phrases. For these phrases, target letters were more likely to be missed if they occurred in a plain form than if they occurred in an ambiguous form of the definite article. Indeed a $t$ test for this comparison yielded $t_{\mathrm{P}}(53)=3.36, p<.001$, and $t_{\mathrm{M}}(30)=3.17, p<.005$. In contrast, a similar $t$ test for the object phrases failed to yield a significant effect of ambiguity $\left[t_{\mathrm{P}}(53)=1.80\right.$, and $t_{\mathrm{M}}(30)=1.32$, both n.s.]. These results accord with our proposal that the functiondisadvantage effect is more pronounced for conditions that afford a smooth extraction of structure.

\section{GENERAL DISCUSSION}

Assuming that the MLE is telling about the analysis of structure that occurs during reading (cf. Koriat \& Greenberg, 1994, 1996), the present study took advantage of certain properties of German to obtain further insight into the nature of the structural frames that are established on line early in text processing. Koriat and Greenberg (1994) assumed that the tentative frames underlying the MLE reflect local structure, possibly phrase-level organi- 
zation only. However, several results reported by them and by others (e.g., Moravcsik \& Healy, 1995; Greenberg \& Koriat, 1991) suggest that these frames are sensitive to structures that extend beyond phrase level. Thus, we reasoned that if structural analysis is to effectively guide and organize semantic analysis, it must be sensitive to the organization of the sentence as a whole, as well as to the relative importance of different phrases within the sentence.

Altogether, the results presented in this article have several implications. First, these results are generally compatible with the structural account of the MLE and are difficult to account in terms of a model that relegates the MLE solely to prelexical or lexical mechanisms. The MLE proved to be sensitive to whether the definite article appeared in a subject noun phrase or in a object noun phrase (Experiments 2 and 4), whether the sentence had the SPO or the OPS format (Experiment 3 ), and whether the definite article helped specify the case of the subject phrase or not (Experiment 4). These interactive patterns would seem to disclose differences in the contribution of the definite article to the evolving structural frame for the sentence.

Second, the results provide important information about the nature and size of the structural frames established. As noted earlier, Koriat and Greenberg (1991, 1994; Greenberg \& Koriat, 1991) tended to stress the contribution of local structure to the MLE. The present results, in contrast, lead to placing an equal emphasis on the organizational processes that pertain to the sentence as a whole. It would seem that the studies emphasizing local structure help to define the necessary conditions for the MLE, which indeed pertain to the context immediately surrounding the critical functor. The present study, however, showed that the magnitude of this effect is also sensitive to structural constraints that extend beyond the immediate surrounding of the critical functor (see, e.g., Moravcsik \& Healy, 1995, 1998). Thus, the SPO format yielded a stronger MLE than did the OPS format, testifying for the contribution of sentence structure. However, the MLE was still observed for the nonstandard OPS format, suggesting that the extraction of structure is sensitive to the organization of the phrase, even when it is embedded in a nonstandard sentential structure.

Third, the results suggest that the magnitude of the MLE for function words increases with the ease with which an effective structural frame can be established on line for the sentence as a whole. Thus, in Experiment 4, the definite article yielded a stronger MLE when it specified unequivocally the case of the initial phrase of a sentence than when it was ambiguous.

Finally, the present study also suggests that the structural frame established during reading is more refined than has been previously thought, reflecting the relative centrality of different phrases within the sentence. Thus, in Experiment 2, the MLE was more pronounced for subject noun phrases than for object noun phrases, and, in Experiment 4, plain phrases revealed a stronger MLE in subject phrases than in object phrases. These results sug- gest that structural articulation is more pronounced for the subject noun phrase, at least for the standard SPO format, possibly because the organization of this initial phrase dominates the organization of the sentence as a whole. If this is true, then we may have here a clue to the manner in which structure extraction proceeds. One possibility is that structural analysis and semantic analysis proceed in a cascaded manner, so that the structural analysis of the first phrase of a sentence leads the way to its semantic analysis, and then the output of both analyses guide the structural analysis of the upcoming phrase, and so forth.

Needless to say, more work is needed to help specify in greater detail the nature of the structural frames established during reading and the processes underlying their establishment. The results obtained in the present study, however, are sufficient to point to the potential value of exploiting the unique properties of different languages to uncover the dynamics of structural extraction during reading.

\section{REFERENCES}

Bates, E., Devescovi, A., Hernandez, A., \& Pizzamiglio, L. (1996). Gender priming in Italian. Perception \& Psychophysics, 58, 9921004.

Buck-Gengler, C., \& Healy A. F. (1993). Letter detection in German silent reading: Issues of unitization and syllable-final devoicing. In Proceedings of the Fifteenth Annual Convention of the Cognitive Science Society (pp, 277-282). Hillsdale, NJ: Erlbaum.

Crawley, R. A., Stevenson, R. J., \& Kleiman, D. (1990). The use of heuristic strategies in the interpretation of pronouns. Journal of Psycholinguistic Research, 19, 245-264.

Drewnowski, A., \& Healy, A. F. (1977). Detection errors on the and and: Evidence for reading units larger than the word. Memory \& Cognition, 5, 636-647.

Ferreira, F. (1994). Choice of passive voice is affected by verb type and animacy. Journal of Memory \& Language, 33, 715-736.

Frazier, L. (1987). Sentence processing: A tutorial review. In M. Coltheart (Ed.), Attention and performance XII: The psychology of reading (pp. 559-586). Hillsdale, NJ: Erlbaum.

FraZIER, L. (1995). Constraint satisfaction as a theory of sentence processing. Journal of Psycholinguistic Research, 24, 437-468.

Givon, T. (1992). The grammar of referential coherence as mental processing instruction. Linguistics, 30, 5-55.

GreenberG, S. N., \& Koriat, A. (1991). The missing-letter effect for common function words depends on their linguistic function in the phrase. Journal of Experimental Psychology: Learning, Memory, \& Cognition, 17, 1051-1061.

Grober, E. H., Beardsley, W., \& Caramazza, A. (1978). Parallel function strategy in pronoun assignment. Cognition, 6, 117-133.

Healy, A. F. (1976). Detection errors on the word "the": Evidence for reading units larger than letters. Journal of Experimental Psychology: Human Perception \& Performance, 2, 235- 242.

Healy, A. F. (1994). Letter detection: A window to unitization and other cognitive processes in reading text. Psychonomic Bulletin \& Review, 1, 333-344.

Healy, A. F., \& Drewnowski, A. (1983). Investigating the boundaries of reading units: Letter detection in misspelled words. Journal of Experimental Psychology: Human Perception \& Performance, 9, 413426.

Hemforth, B. (1993), Kognitives Parsing: Repräsentation und Verarbeitung sprachlichen Wissens [Cognitive parsing: Representation and processing of linguistic knowledge]. Sankt Augustin, Germany Infix.

Konieczny, L., Hemforth, B.. Scheepers, C., \& Strube, G. (1996). 
Reanalysen vs. interne Reparaturen beim Sprachverstehen [Reanalyses vs. internal repairs in language comprehension]. In C. Habel, S. Kanngießer, \& G. Rickheit (Eds.), Perspektiven der kognitiven Linguistik (pp. 161-183). Wiesbaden: Westdeutscher Verlag.

Koriat, A., \& GreenberG, S. N. (1991). Syntactic control of letter detection: Evidence from English and Hebrew nonwords. Journal of Experimental Psychology: Learning, Memory, \& Cognition, 17. 1033-1048.

Koriat, A., \& Greenberg, S. N. (1994). The extraction of phrase structure during reading: Evidence from letter detection errors. Psychonomic Bulletin \& Review, 1, 345-356.

Koriat, A., \& Greenberg, S. N. (1996). The enhancement effect in letter detection: Further evidence for the structural model of reading. Journal of Experimental Psychology: Learning, Memory, \& Cognition, 22, 1184-1195.

Koriat, A., Greenderg, S. N., \& Golddhmid, Y. (1991). The missingletter effect in Hebrew: Word frequency or word function? Journal of Experimental Psychology: Learning, Memory, \& Cognition, 17, 66 80.

MacDonald, M. C. (1996). Representation and activation in syntactic processing. In T. Inui \& J. L. McClelland (Eds.), Attention and performance XVI: Information integration in perception and communication (pp. 433-456). Cambridge, MA: MIT Press.

Mecklinger, A., Schriefers, H., Steinhauer, K., \& Friederici, A. D. (1995). Processing relative clauses varying on syntactic and semantic dimensions: An analysis with event-related potentials. Memory \& Cognition, 23, 477-494.

Moravcsik, J. E., \& Healy, A. F. (1995). Effect of meaning on letter detection. Journal of Experimental Psychology: Learning, Memory, \& Cognition, 21, 82-95.

MoravcsiK, J. E., \& Healy, A. F. (1998). Effect of syntactic role and syntactic prominence on letter detection. Psychonomic Bulletin \& Review, 5, 96-100.

MüsSELER, J. (1995). Focusing and the process of pronominal resolution. In G. Rickheit \& C. Habel (Eds.), Focus and coherence in discourse processing (pp. 52-73). Berlin: de Gruyter.

Pechmann, T., Uszkoreit, H., Engelkamp, J., \& Zerbst, D. (1996) Wortstellung im deutschen Mittelfeld: Linguistische Theorie und psycholinguistische Evidenz [Word sequence in German midfield: Linguistic theories and psycholinguistic evidence]. In C. Habel, S. Kanngießer \& G. Rickheit (Eds.), Perspektiven der kognitiven Linguistik (pp. 257-299). Wiesbaden: Westdeutscher Verlag.

Radeau, M., \& van Berkum, J. J. A. (1996). Gender decision. Language \& Cognitive Processes, 11, 605-610.

Rickheit, G., GÜNTher, U., \& SiChelsChmidt, L. (1992). Coherence and coordination in written text: Reading time studies. In D. Stein
(Ed.), Cooperating with written texts: The pragmatics and comprehension of written texts (pp. 103-127). Berlin: de Gruyter.

Rösler, F., Pechmann, T., Streb, J., Röder, B., \& Henninghausen, E. (1998). Parsing of sentences in a language with varying word order: Word-by-word variations of processing demands are revealed by event-related brain potentials. Journal of Memory \& Language, $\mathbf{3 8}$, $150-176$

Saint-Aubin, J., \& Poirier, M. (1997). The influence of word function in the missing-letter effect: Further evidence from French. Memory \& Cognition, 25, 666-676.

SChriefers, H., Friederici, A. D., \& Rose, U. (1998). Context effects in visual word recognition: Lexical relatedness and syntactic context. Memory \& Cognition, 26, 1292-1303.

SIDNER, C. L. (1983). Focusing and discourse. Discourse Processes, 6 , $107-130$.

Steinhauer, K., Mecklinger, A., Friederici, A. D., \& Meyer, M. (1997). Wahrscheinlichkeit und Strategie: Eine EKP-Studie zur Verarbeitung syntaktischer Anomalien [Probability and strategy: An ERP-study on the process of syntactic anomalies]. Zeitschrift für Experimentelle Psychologie, 44, 305-331.

van DiJk, T. A., \& KinTSCH, W. (1983). Strategies of discourse comprehension. New York: Academic Press.

\section{NOTES}

1. Note, in German, there are only two additional three-letter content words with the initial letter $d$ : Duo (duet) and Dur (major). They were excluded because Duo is an unusual foreign word, and Dur is used only in the context of musical notation (e.g., $C$-Dur standing for $C$-major).

2. The absence of a main effect for phrase case (nominative vs. accusative) might have seemed to be inconsistent with the results of Experiment 2, which yielded more omission errors for the subject phrase than for the object phrases. Recall, however, that unlike in Experiment 2, the subject phrases used in this experiment consisted of coordinating structures with the critical word located in the second part of the coordination ("A true gentleman and a lady ..."; see examples in Appendix A). Additionally, this word is associated with the prior content word. It is known from Rickheit, Günther, and Sichelschmidt's (1992) study that coordinated noun phrases require additional processing time, especially at the end of the phrase, which might improve letter detection. Therefore, a comparison of the nominative case in both experiments should be regarded with caution.

3. Note that, in German, a sentence like "Die Dame verehrt Hans" would be completely ambiguous because it could mean "The lady worships Hans" as well as "Hans worships the lady." Such completely ambiguous sentences were not used in these experiments.

\section{APPENDIX A}

Examples of the subject-predicate-object (a) and object-predicate-subject (b) formats in Experiment 3 and their English translations. Critical words are in italics. In the English translation, words in brackets are added to clarify the meaning of the sentence.

\section{A Content Word in a Nominative Phrase}

(a) EIN WAHRER GENTLEMAN UND EINE DAME GEBEN EINEM PORTIER

EINES HOTELS STETS EIN ADÄQUATES TRINKGELD.

(A true gentleman and a lady give a porter of a hotel always an appropriate tip.)

(b) STETS EIN ADÄQUATES TRINKGELD GEBEN EIN WAHRER GENTLEMAN

UND EINE DAME EINEM PORTIER EINES HOTELS.

(Always an appropriate tip give [is given by] a true gentleman and a lady [to] a porter of a hotel.)

\section{A Function Word in a Nominative Phrase}

(a) SOWOHL DER AUTOR ALS AUCH DER VERLAG HABEN AN DEM

BESTSELLER GUT VERDIENT.

(The author as well as the publisher have made a good profit from the bestseller.) 


\title{
APPENDIX A (Continued)
}

(b) AN DEM BESTSELLER GUT VERDIENT HABEN SOWOHL DER AUTOR ALS AUCH DER VERLAG.

(From the bestseller have made [The bestseller contributes to] a good profit [by] the author as well as [by] the publisher.)

\section{A Content Word in an Accusative Phrase}

(a) VIELE POLIZISTEN BEGLEITEN EINE GROSSE DEMO AUF DER LEOPOLDSTRASSE. (Many policemen escort a big demonstration on the Leopold street.)

(b) EINE GROSSE DEMO AUF DER LEOPOLDSTRASSE BEGLEITEN VIELE POLIZISTEN. (A big demonstration on the Leopold street [is] escort[ed by] many policemen.)

\section{A Function Word in an Accusative Phrase}

(a) DER SOLDAT ERWIES DEM GENERAL STETS DEN NÖTIGEN RESPEKT. (The soldier always pays [the] respect to the general.)

(b) STETS DEN NÖTIGEN RESPEKT ERWIES DER SOLDAT DEM GENERAL. (Always [the] respect pays [is paid by] the soldier to the general.)

\begin{abstract}
APPENDIX B
Examples of plain (a) and ambiguous (b) function-word sentences in Experiment 4 and their English translations. Critical words are in italics. In the English translation, words in brackets are added to clarify meaning of the sentence.

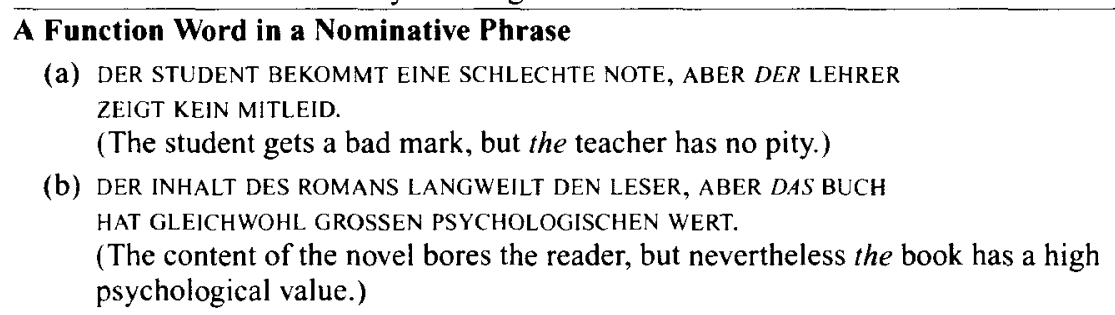

\section{A Function Word in an Accusative Phrase}

(a) DER STUDENT BEKOMMT EINE SCHLECHTE NOTE, ABER DEN LEHRER MAG HANS TROTZDEM.

(The student gets a bad mark, but the teacher [is] like[d by] Hans nonetheless.)

(b) DER INHALT DES ROMANS LANGWEILT DEN LESER, ABER DAS BUCH EMPFIEHLT EIN PROFESSOR DES SEMINARS.

(The content of the novel bores the reader, but the book [is] recommend[ed by] a professor of the seminar.)

(Manuscript received October 19, 1998; revision accepted for publication October 26, 1999.) 